\title{
Editorials
}

\section{The future of national health systems}

Comprehensive national health systems providing universal access, based on social solidarity and funded through social insurance or general taxation, have been one of the major achievements of many countries in the period following the Second World War. Yet everywhere these systems are now under threat. Costs are increasing because of rapid developments in health care technologies, many of which are very expensive, at least initially, and because of ageing of the population which has occurred at least in part because of the very healthcare systems now threatened by their own success.

Elected representatives are telling citizens that national health systems are becoming unaffordable, and many are attempting to persuade their electorate that the only solution is a greater or lesser degree of commercialisation and privatisation. This is perplexing when there is much accumulating evidence that heavily privatised systems, most powerfully illustrated by the situation in the United States, produce poorer health outcomes at greater cost and with worse health inequalities. ${ }^{1} \quad$ Market competition legitimises the pursuit of private profit and also the pursuit of individual advantage at the expense of others. Patients are no longer citizens bound by ties of mutual responsibility, but consumers out for the best bargain. 'Quality' is framed as customer satisfaction and the scope of choice, and actively distanced from the reality of care. ${ }^{2}$

\section{FUTILITY AND FEAR}

Other much more insidious factors inflate healthcare costs to an extent which is difficult to measure but which is almost certainly more threatening and more difficult to contain. These 'inflationary' factors are futility and fear.

As more and more people live into very old age, there is an increasingly urgent need to address the issue of futile and expensive treatments at the end of life. Average longevity is used as the principal metric of the effectiveness of health systems, and yet extreme longevity has become a source of considerable suffering. Death at any age seems to be portrayed as failure and this, in turn, adversely affects the care of the dying, which is in itself a core task for health systems. As the body ages, irreversible changes become widespread and are not confined to one organ or one disease process. More and more medications and interventions are applied to the failing body, often displacing the intimate hands-on care that is needed. These ever more complex regimens become, in turn, a significant cause of further harm. The average number of medicines now taken by those over 70 years makes adverse effects probable rather than possible. ${ }^{3}$

Adverse medication events are a leading cause of mortality and morbidity in older people and an enormous cost to health systems, yet these remain invisible in system level measures which only reflect the positive effects of adding treatments. In the future, the quality of healthcare for an ageing population with multiple comorbidities is more likely to be reflected in how well clinicians make decisions not to use treatments.

Very few of the interventions are grounded in evidence because there are still very few studies of the effects of pharmaceuticals on old people with significant comorbidity. And this comes on top of the endemic problem of the distorted reporting of research studies, especially those funded by the pharmaceutical industry, which tend to exaggerate the benefits and minimise the harms of treatments.

Futility is perhaps even more prevalent when preventive (as opposed to treatment) technologies are applied to those who have already exceeded the average expectation of life. For example, the use of statins in this age group does seem to reduce cardiovascular deaths but they do not extend life and, by closing off one cause of death, they inevitably open others, exposing old people to an increased likelihood of being diagnosed with cancer or dementia. ${ }^{4}$

\section{THE IMPACT OF PERCEIVED HEALTH THREATS}

Those of us fortunate enough to live in the rich countries of the world are living longer and healthier lives than ever before and yet we seem to be more fearful for our health than ever before. The more we are exposed to modern medicine, the iller we seem to feel, ${ }^{5}$ thus proving the truth of GK Chesterton's assertion that:

'The trouble with always trying to preserve the health of the body is that it is so difficult to do without destroying the health of the mind."

The more heightened the rhetoric of preventive health, the more those currently in good health are invited to consider the possibility, however remote, of lurking disease. Time and a great deal of money are spent cajoling individuals to eat better, exercise more, drink less, and stop smoking with disappointingly little overall effect, while structural primary prevention by government and policy makers is under used, even though increasing tax on tobacco and alcohol and decreasing tax on healthy food is known to be effective and to reduce inequity.

Enormous amounts of money are expended on screening programmes with only marginal benefits and significant harms that are rarely explained to those targeted. This is particularly true for cancer screening where the problems of overdiagnosis, which blights healthy lives, are becoming ever clearer. ${ }^{7}$ The fundamental problem is the impossibility of clearly distinguishing between malignant and non-malignant tissue. ${ }^{8}$

\section{THE DISAPPEARANCE OF NORMAL}

The concept of normal variations of health is disappearing from medicine. We are systematically lowering the thresholds for the diagnosis of disease which becomes ever further disconnected from suffering. More and more people, previously regarded as healthy, are being labelled as sick, and the proposed new edition of the Diagnostic

\section{"The more heightened the rhetoric of preventive health, the more those currently in good health are invited to consider the possibility, however remote, of lurking disease.}




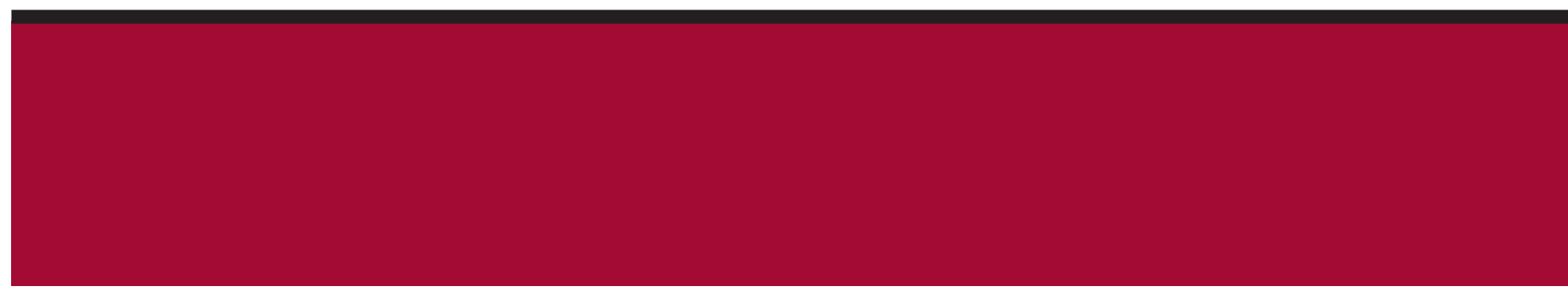

"However, no system funded on the basis of social solidarity can possibly cope when demand for health care is transformed into need by the systematic escalation of fear."

and Statistical Manual of Mental Disorders threatens to turn every variant of existential distress and human eccentricity into serious mental illness usually requiring pharmaceutical relief. ${ }^{9}$

We are living through a historical moment within which it has seemed possible that technology can protect us from suffering and death. National health budgets are held hostage to misplaced hope by a range of new cancer treatments offering minimal and often clinically insignificant increments of life extension at the expense of remaining quality of life: an unaffordable exercise in cost-futility. ${ }^{10}$

The moment will pass as its deficiencies become apparent; but, how can national health systems based on mutuality and inclusiveness survive in the meantime? A firm foundation in primary care will be essential with well-trained generalist physicians and nurses able to integrate care around the needs and values of each particular individual, so producing more acceptable health outcomes at an affordable cost. Need and expectation will have to be more intelligently managed through informed and shared decisionmaking.

More fundamentally, citizens and their elected representatives will need to become much more intimately acquainted with the constraints of human biology and the inevitability of death. A mature debate about the futility of expensive treatments in the old, the frail, and others nearing the end of life will be essential. As individuals, how should we approach death and its causes: as doctors, how should we accept death and its causes; as a society, how should we provide care at the end of the lifespan?

Existing national health systems have the capacity to respond to healthcare needs for the treatment of disease and for the relief of pain and suffering. However, no system funded on the basis of social solidarity can possibly cope when demand for health care is transformed into need by the systematic escalation of fear. If genuinely inclusive national health systems are to survive, that fear will have to be addressed.

\section{Iona Heath,}

President, Royal College of General Practitioners, London, UK.

\section{Dee Mangin,}

Senior Lecturer, Christchurch School of Medicine, Public Health and General Practice, Christchurch, New Zealand.

\section{Les Toop,}

Professor, University of Otago, Christchurch, New Zealand.

\section{John Brodersen,}

Faculty of Health Sciences University of

Copenhagen, The Research Unit and Section for General Practice Department of Public Health, Copenhagen, Denmark.

\section{Provenance}

Commissioned; not externally peer reviewed.

DOI:10.3399/bjgp11X572292

\section{ADDRESS FOR CORRESPONDENCE}

Iona Heath

Royal College of General Practitioners, 1 Bow Churchyard, London, EC4M 9DQ, UK.

E-mail: iona.heath22dayahoo.co.uk

\section{REFERENCES}

1. Starfield B. Is US health really the best in the world? JAMA 2000; 284(4): 483-485.

2. Mol A. The logic of care: health and the problem of patient choice. Abingdon: Routledge, 2008.

3. Boyd CM, Darer J, Boult C, et al. Clinical practice guidelines and quality of care for older patients with multiple comorbid diseases: implications for pay for performance. JAMA 2005; 294(6): 716-724

4. Mangin D, Sweeney K, Heath I. Preventive health care in elderly people needs rethinking. BMJ 2007; 335(7614): 285-287.

5. Sen A. Health: perception versus observation. BMJ 2002; 324(7342): 860-861.

6. Chesterton GK. Illustrated London News 1929; 10 Aug

7. Gøtzsche PC, Nielsen M. Screening for breast cancer with mammography. Cochrane Database Syst Rev 2009; 4: CD001877.

8. Löwy I. Preventive strikes: women, precancer, and prophylactic surgery. Baltimore, MA: The Johns Hopkins University Press, 2010.

9. Frances A. It's not too late to save 'normal'. Los Angeles Times 2010; 1 Mar: http://www.latimes.com/news/opinion/la-oefrances1-2010mar01,0,1656826.story laccessed 12 Apr 2011).

10. Mason AR, Drummond MF. Public funding of new cancer drugs: is NICE getting nastier? Eur J Cancer 2009; 45(7): 1188-1192. 